\title{
Experimenting with Academic ESL: An ESL/Sociology Link
}

\author{
Gail August ${ }^{1}$ \\ ${ }^{1}$ Hostos Community College, City University of New York (CUNY), Bronx, New York, USA \\ Correspondence: Gail August, Department of Language and Cognition, Hostos Community College, City \\ University of New York (CUNY), 500 Grand Concourse, Bronx, New York, 10451, USA. Tel 1-718-518-6602. \\ E-mail: gaugust@hostos.cuny.edu
}

Received: June 27, 2018 Accepted: August 7, 2018 Online Published: August 8, 2018

doi: 10.5539/elt.v11n9p33 URL: http://doi.org/10.5539/elt.v11n9p33

\begin{abstract}
To improve academic ESL, a community college has been experimenting with linking an ESL class to a Sociology class. The primary goal was to use the methodology of Content Based Instruction to develop a curriculum that would promote academic vocabulary acquisition, critical thinking, and authentic communication in a sheltered environment. The paradigm of Action Research was used as a framework to reflect on the strengths of the program and to identify activities that engaged the students and contributed to improved language skills. Supplementary assignments of a Young Adult novel and provocative movies, used across both the ESL and Sociology class, helped students to apply abstract concepts to familiar situations. The structure of the link produced an effective learning community and a support system for the students. We suggest that linking ESL to a content course might be preferable to other options for developmental ESL students entering college.
\end{abstract}

Keywords: authentic communication, community college, CBI, critical thinking, developmental education, ESL, learning community, sheltered instruction, vocabulary

\section{Introduction}

A community college has been experimenting with linking English as a Second Language (ESL) classes with academic courses. During the last three years we have explored several teaching strategies in a program which links ESL to a full-credit content course. Our primary motivation was to familiarize students with academic college life in a sheltered supportive environment. Another purpose of our program was to find activities to accomplish the specific educational goals of academic vocabulary acquisition, authentic communication, and critical thinking. Using the paradigm of Action Research to reflect on the strengths of our program, we have identified assignments and activities used across both the ESL and content course that were useful in promoting our pedagogic goals. We also observed positive qualitative outcomes from our program, as it fostered a sense of community and student engagement. We suggest that linking ESL to a content course might be preferable to other options for developmental ESL students entering college.

\section{The Problem: Options for Remediation}

One of the problems faced by community colleges in the US and Canada is how to educate large numbers of entering students whose academic skills are below college level (Bailey, Jaggars, \& Jenkins, 2015). When students do not meet academic requirements in reading, writing, or math, they have generally been placed into remedial or developmental programs to improve their skills. [In US colleges, "developmental" and "remedial" are used interchangeably to classify students and courses that are below college-level proficiency.] Immigrant students who have low English proficiency are also customarily assigned to developmental programs for ESL instruction.

The remediation/developmental situation in community colleges involves large numbers of students. It is estimated that more than half of the community college students in the US will need some kind of remediation before beginning a college program (Shields \& O'Dwyer, 2017). For example, at the City University of New York, about 80 per cent of students entering community colleges do not pass at least one of the three entrance assessments of reading, writing, or pre-college math (Harris, 2017). Although most of the information about this situation comes from US-based research, Canadian colleges also face this problem. According to Fisher and Engemann (2009), 18.5 per cent of the 15,000 students entering a large Canadian comprehensive community college needed remediation (an academic upgrading course) to improve skill deficiencies in literacy or 
mathematics.

There are three general approaches to preparing developmental and ESL students for college. The first places students into non-credit developmental classes offered by the college. The second option is to offer non-credit pre-college workshops held outside of the college setting, providing intensive training in targeted weaknesses. A third approach is to immerse students in college studies and college life while they are taking developmental and/or ESL classes to improve their academic skills.

With the first option, non-credit developmental courses offered by the college, students can also enroll in college-level courses, but their choices are restricted. Additionally, there is no supplementary support for the college-level courses. Research studies show that remediation done within the college has some very consequential disadvantages, as it takes too much time, is expensive, and may discourage students (Shapiro et al., 2016; Shields \& O'Dwyer, 2017). Students pay tuition or use part of their financial aid, but do not receive full college credit or make progress toward a degree. Non-credit courses prolong the time in college, which adds to the problem of degree completion for community college students. According to Shapiro et al. (2016), over 31 per cent take more than six years to complete a two-year degree. This extended educational process creates financial and psychological burdens, and may become a deterrent to students with work and family obligations. In addition to these concerns, studies show little consensus about whether such programs produce significant educational improvements (Goldrick-Rab, 2010; Shields \& O’Dwyer, 2017).

The other two options address the problems of prolonged time in college and the psychological stress created by slow progress to a degree. The second option, pre-college workshops and programs operating independently of the college, eliminates the financial disadvantages associated with developmental courses. However in these courses, students work on targeted skill deficiencies outside of the college environment, unconnected to the overall college experience. The third option is to link developmental courses to college-level courses, with the objective of exposing students to the complete college experience as soon as possible. Our ESL program presents an example of the third option, combining ESL with a linked college-level content course.

\section{The Setting}

Our college is the only one of the 20 undergraduate CUNY colleges to award some academic credit for ESL. We offer four levels of ESL, where students receive nine hours of instruction each semester and earn three academic credits, counted as electives. ESL students are placed in classes on the basis of a writing exam. These classes are capped at 25 students and follow a lecture, discussion, group-work format, focusing on the four language skills of reading, writing, listening, and speaking. Recently, our college has been developing ESL links with content courses. The content courses are full-credit courses which satisfy General Education requirements and will transfer to any CUNY two- or four-year college. The following discussion describes an ESL/Sociology link with a Level Three ESL class.

\section{Background}

\subsection{Sheltered Classes and Learning Communities}

Academic research shows that sheltered classes and learning communities help students to feel more comfortable at college and build confidence in their academic potential (Knoblock \& Youngquist, 2016). In a meta-analysis of over 300 studies, Johnson, Johnson, and Smith (2014) show that learning communities improve college outcomes by providing more integration into the college as well as social pressure for academic achievement. In a Canadian study, Fisher and Engemann (2009) found that student engagement was the most important factor in promoting student success and college retention. Knoblock and Youngquist (2016) share positive anecdotal responses from students in learning communities, reporting that they create feelings of belonging and a sense of family or community. Krashen (2015) suggests that sheltered classes and learning communities also produce better ESL and content learning.

Learning communities can have a positive effect on teachers as well as students. In a study at a community college, instructors reported that participation in linked courses and learning communities produced better interactions with the students. In addition, faculty described increased job satisfaction as a result of developing new relationships with colleagues, learning about another discipline, and engaging in collaborative studies and presentations (Jackson, Stebleton, \& Laanan, 2013).

\subsection{Content-Based Instruction}

Many educators believe that Content-Based Instruction (CBI), where language is the medium for transmitting content and content is the vehicle for learning language, is an excellent methodology for ESL (Cammarata, Tedick, \& Osborn, 2016). [CLIL, content and language integrated learning, is a comparable methodology, used 
in European countries.] According to Larsen-Freeman and Anderson (2013), CBI results in more effective language acquisition, authentic communication, better linguistic preparation for academic studies, and the opportunity to develop critical thinking (CT) skills. Rogers and Rogers (2014) claim that CBI encourages authentic communication, which is necessary for successful language instruction. CBI is a more comprehensive methodology than ESP (English for Special Purposes), which generally focuses on more specialized workplace or professional content (Larsen-Freeman \& Anderson, 2013).

CBI is also considered a good curriculum for promoting CT, an academic skill considered essential for academic achievement (Krathwohl, 2002). The concept of CT, attributed to ideas developed by Benjamin Bloom and his colleagues in the 1950s, encompasses skills which encourage students to respond to and process information rather than to memorize and restate someone else's ideas. Such skills include interpretation, explanation, analysis, synthesis, evaluation, making inferences, the integration of previous knowledge with new information, and the formulation of personal ideas and opinions (Adams, 2015). Because CBI presents a variety of materials on a specific topic, it is an effective curriculum for CT. When students confront multiple curricular sources, there are many opportunities for comparison, analysis, evaluation, and interpretation (Stoller \& Fitzsimmons-Doolan, 2016).

\subsection{Vocabulary Acquisition}

Vocabulary knowledge is an essential condition for success in college and many educators feel that command of academic vocabulary may be the most important factor in students' college achievement (Anstrom et al., 2010). For ESL students, deficiencies in academic vocabulary present a significant obstacle, and educators suggests that vocabulary development should be one of the main objectives of any ESL curriculum (Gibson, 2016).

According to Gibson (2016), vocabulary disparities between ESL students and their native-speaking peers exist from pre-kindergarten to college. Estimates for college reading requirements suggest that that most ESL students are likely to begin their studies with an enormous vocabulary gap. Nation (2001) states that an educated native-speaking adult knows about 20,000 word families. Understanding 98 per cent of a written text requires knowledge of 8,000 to 9,000 word families (about 20,000 to 35,000 words); understanding 95 per cent would require about 4,000 to 5,000 word families. The 95 per cent goal is the lowest threshold for coping with college materials (Agernas, 2015; Nation, 2001). It is logical to assume that the English vocabulary of most entering ESL students would fall significantly below the 4,000 to 5,000 word family goal recommended for effective college reading.

Educators recommend that instructors work to identify the best practices to accomplish the goal of academic vocabulary acquisition (Gibson, 2016; Nation, 2001). Vocabulary acquisition requires exposure in context, and to learn a word, it must be encountered several times in multiple situations (Bisson, Heuven, Conklin, \& Tunney, 2014). CBI provides many opportunities for repetition. Students who read and discuss multiple sources related to a single topic are thus exposed to a recycling of relevant academic vocabulary in various contexts, making it more likely that vocabulary will be learned and remembered (Snow, 2016). Cognitive science research describes vocabulary acquisition by explaining that a word is successfully learned when it is stored in long-term memory and accessible for use when necessary (Kennedy, 2006). Kennedy (2006) advocates for a CBI curriculum, suggesting that effective long-term vocabulary storage is more likely to occur when students are able to participate in activities that promote learner engagement by using CT skills.

Nation and Webb (2011) explain why an ESL/CBI link presents an optimal opportunity for learning vocabulary. Content links reduce vocabulary load, increase repetitions, provide better outcomes when guessing meaning from context, encourage productive as well as receptive vocabulary, and organize new vocabulary into a familiar knowledge framework. In CBI, content is limited to one wide topic area such as sociology, which means a smaller vocabulary input of low frequency words. There are many opportunities for repetitions of relevant vocabulary words, including high frequency words, low frequency academic words, and technical words. As students build up knowledge in one subject area, topics covered in the reading materials become more familiar, making it easier to guess the meaning of new words from context. In vocabulary acquisition, production reinforces the knowledge of words, and in a CBI curriculum, students have many occasions for oral practice with new vocabulary. Because vocabulary learning is connected to familiar information, storage and recall are more efficient.

\section{Methodology: Action Research}

We have used the paradigm of Action Research (AR) to provide a framework to reflect on our program. AR originated in the 1950s with the social-psychology work of Kurt Lewin (Mills, 2016). Its orientation is to produce knowledge and information, using the context of practice and practitioners (Bradbury-Huang, 2010). It 
is designed to help teachers improve their craft and is particularly well-suited to small-scale situations (Wallace, 2006). In educational AR, instructors identify a problem and explore different approaches to address this problem. Educators reflect on their classroom activities, looking for explanations for successful interventions. The goal is to use the expertise and perceptions of the instructor to find and share information that will improve teaching practices (Mills, 2016).

We have decided that AR provides the best framework to discuss and reflect on our program. Our ESL/Sociology link was not conceptualized as a traditional research study. Because we wanted the insight and input from different members of the faculty, we have worked with three ESL instructors and two sociology instructors. In the ESL classroom, we have experimented with various films and two different textbooks, one that is primarily focused on sociology themes, Academic Encounters Level 3 (Williams, Brown, \& Hood, 2012) and another which is a general reading book with topics on business, health, crime, social deviance, education, and culture, Longman Academic Reading Series 3 (Miller \& Cohen, 2013). The sociology program uses Sociology: A Brief Introduction, Edition 12 (Schaefer, 2016), but has alternated between assigning a textbook with using the online adaptation.

There are also other features which motivated us to reflect on the link from a descriptive orientation. Selection factors influence those who participate in this kind of program: ESL teachers who enjoy collaboration, sociology instructors who are experienced with ESL, and students who decide to elect these linked classes. Comparisons would be complicated using student performance in the sociology class. The linked sociology class is limited to 25 students, while the regular sociology classes have 40 students. It is also sheltered and taught by an instructor trained in ESL education. We have also found it difficult to compare grades across ESL classes, as they are very dependent on individual student's strengths and weaknesses in English, personal circumstances (such as working and family obligations), and the influence of different teachers and teaching styles. In addition, because we teach an untraditional population, conclusions based on college persistence can be unrealistic. Students have many life contingencies that may require them to leave college prematurely. Challenges like economics, family circumstances, child care arrangements, housing, change of residence, work schedules, and legal or health complications must be factored into evaluations involving community college perseverance and graduation rates (Cohen \& Brawer, 2003).

This variability in our program is typical of many community college situations. However, despite conditions which might sometimes contravene conventional research paradigms, our instructors are experienced and involved practitioners and we are able to reflect on and modify our projects to improve our teaching. AR gives us a perspective to investigate important educational challenges and to discuss and communicate our interpretations.

\subsection{Applying Action Research to the ESL/Sociology Link}

AR methodology begins with identifying a problem or an area of focus for change (Mills, 2016). Our original challenge was to design a new kind of option for developmental ESL students. Beyond this, we wanted to create a program that would make ESL education more relevant to our students, and offer a strong foundation for their future college courses. Our specific pedagogic goals were to develop a curriculum that would promote academic vocabulary acquisition, $\mathrm{CT}$, and authentic communication in classroom discussions. We also wanted our program to provide a supportive environment for the students.

Our ESL/Sociology link was created in response to the challenges of developmental ESL and with the goal of designing a curriculum to accomplish some of the stated pedagogic objectives. Using the perspective of AR, we developed procedures to examine and modify our program. The faculty members involved in the link have experimented with different ideas and assignments. Instructors share weekly emails, conduct regular meetings, and participate in discussions at the end of the semester to exchange insights about what worked well and what needs to be modified. As a result of this process, we have identified activities that engaged the students and improved their language skills. In addition, we have come to understand how the structure of the link supports our goals of student engagement and academic growth.

\subsection{Activities: Curriculum for Authentic Communication}

The model for our ESL/Sociology program was consistent with the methodology of CBI, a pedagogy which is used in all of our ESL classes. Linking ESL to a content course is a logical way to provide authentic content for a CBI curriculum. In the ESL class, the content is built around sociological topics and reading and writing assignments are discussed from a sociological perspective. The sociology class, which provides the academic content for the ESL link, is taught as a conventional Introduction to Sociology course. The sociology curriculum satisfies the objective of authenticity, leading to authentic communication, as it provides authentic college 
materials and an authentic college experience. There is, however, an important caveat to this assumption of authenticity, because when students find academic materials abstract and detached from their own experience, they may be discouraged from participation, negating possibilities for authentic communication. According to Miller, Berkey, and Griffin (2015), students are more likely to respond to school materials that relate to their own circumstances and foster personal engagement. We found that adding a book and movies to the curriculum made the sociology content more comprehensible, provided concrete examples for student discussions, and increased possibilities for authentic communication.

The book we assigned, Girl in Translation, by Jean Kwok (2010), is a Young Adult novel based on the author's experience as an immigrant. The themes of immigration, gender roles and stereotypes, social class, culture, family, education, life choices, and social status were good topics for sociological discussions. To coordinate the link, the ESL class concentrated on plot, sequence, character development, vocabulary, and cultural references, while the sociology teacher analyzed the book in the context of sociological theories. In addition to the book, we have introduced movies to be discussed in both the ESL and sociology class. Two films, "The Central Park Five," for themes of race, crime, social justice, social class, and education, and "Hidden Figures," for themes of race, education, and gender, produced animated discussions and motivation for class compositions.

Both the book and the movies were helpful in linking the two courses and they also made the abstract content of sociology more concrete and easier to understand. Students discussed how to apply two major sociological theories, Functionalist Theory and Conflict Theory, to their interpretations of characters and events. Functionalist Theory, describing the relationship of the components of society to produce stability, was used to understand current social conditions, while Conflict Theory, describing the roles of coercion and power, was applied to situations when characters struggled to create social change. For example, the racism in both movies was explored in terms of Functionalist Theory, while efforts of the characters to make changes in their lives were seen as examples of Conflict Theory. Students discussed how their own situations often required strength and determination to move from the status quo, described by Functionalist Theory, in order to improve their lives. The unconventional choices made by the protagonist of Girl in Translation resonated with decisions made by some of the students, and were understood as an example of Conflict Theory. Those who had experiences with the criminal justice system, either in the US or elsewhere, were able to make meaningful comparisons with the young victims in "The Central Park Five." The women in the class were particularly responsive to the traditional gender expectations in "Hidden Figures" and how they corresponded to those in their home cultures, reflecting upon how Functionalist Theory might explain why people supported outdated ideas about gender.

Because students were able to compare relevant situations in the book and movies to their own families and social circumstances, there were many opportunities for student engagement and authentic communication. As students became more comfortable with the sociological material and more familiar with their classmates, discussions became increasingly enthusiastic. In these class interactions, we observed evidence of the productive use of academic vocabulary as well as CT and content learning.

\subsection{Link Structure: Student Engagement and Academic Growth}

The structure of our program also produced positive social, psychological, and pedagogical advantages. The ESL/Sociology link formed a learning community, which has been shown to result in a better social and educational experience. The sociology course is sheltered, as it includes only the ESL cohort and the teacher is experienced with the ESL population. Because the students in the link shared the same classes, meeting 12 hours a week, friendships and support groups naturally developed. As the semester progressed, the teaching and learning atmosphere became increasingly relaxed and students formed good working relationships. We have observed that even after students leave the ESL program, they have continued to maintain these link friendships.

The structure of the program also had other pedagogical advantages. It clarified the academic objectives for both courses, providing a solution to CBI questions about how to balance language and content and how to fairly assess students. The sociology instructor graded students on tests, projects, and classwork that demonstrated knowledge and understanding of the sociology materials. The ESL class focused on language skills and students were graded on these skills, but also on their proficiency in integrating sociological concepts into their discussions and writing. The link also gave the students a more academic experience with the content material than would be possible in a typical ESL/CBI curriculum. Students had to learn how to study terms and theories, and also how to prepare for sociology tests. Many found this new and challenging. In addition, the sociology class was taught by a $\mathrm{PhD}$ professor who is a specialist, rather than an ESL teacher working with content materials. The richness, depth, and challenges of academic content material are an important aspect of a college education, and students in the link were able to participate fully in this kind of scholastic experience. 
Production is an important vehicle for vocabulary acquisition and the vocabulary production advantages of the link are particularly significant. ESL students rarely get opportunities for oral vocabulary practice in conventional content classes. According to student reports and faculty observations, ESL students are generally reluctant to speak in a non-ESL college class. They often sit in the back, seldom participate, and are uncomfortable about asking the teacher to define a word or to speak more slowly. In contrast, the content class in the link presented students with three additional weekly class hours to practice their oral skills with new vocabulary in a sheltered classroom situation.

\section{Conclusion}

Our observations suggest that ESL content links contribute to college readiness. Many students enter our colleges without a clear concept of how to study or how to approach academic disciplines. Pre-college workshops and tutoring include study skills and time management skills, but for some students, these issues do not become tangible until they are encountered in a college environment, when they are carrying a full course load. Like all new college students, ESL students confront many different challenges such as balancing study time with other obligations, and negotiating college facilities. Being in college raises the stakes, the anxiety, and the motivation. It can be helpful to first experience these college-life realities in a transitional sheltered environment. This ESL link lasts one semester and the students will eventually move into content courses which include students who are not ESL. However, because the content course is not in any way diluted or abridged, the link helps to prepare students for mainstream courses.

Goldrick-Rab (2010) states that a rigorous research agenda is needed to identify the best practices for community college success. Our program satisfies two of her recommendations, contextualized learning and learning communities. Our program also meets two suggestions from Bailey (2009), bringing students into college-level classes as soon as possible and providing support for them in those classes. If we had found a way to triangulate our AR processes with a quantitative methodology, this would have been a more powerful study. However, we were not able to reliably identify analogous student populations and situations for comparisons. In the future, it would be interesting to find ways to replicate this kind of endeavor with more classes, including large numbers of students and several colleges, with agreed upon quantitative procedures for comparing student performance.

AR offers a perspective to reflect upon educational innovations. Although this discussion involves a small program, many of our ideas can be implemented in other similar educational situations. Using insights from AR methodology, we have identified specific strengths and directions for working with developmental ESL students. The ESL/Sociology link provided CBI instruction with authentic content, and many different kinds of opportunities to use CT, practice academic vocabulary in receptive and productive situations, and engage in meaningful ommunication. Particularly successful activities were a novel and provocative movies that were discussed in both classes. There were also important qualitative advantages to the link, as the structure of the program fostered a sense of group solidarity that promoted college engagement. In addition, teachers involved in the link were energized by creating new curriculum and sharing ideas.

Programs such as our ESL/Sociology link provide an alternative to pre-college courses and skill-development workshops. In the link, students can work with authentic academic materials, engage in challenging discussions, apply abstract concepts to real life situations, and improve their language skills. They are also able study academic content with a $\mathrm{PhD}$ expert. With this kind of program, students can develop a supportive relationship with their classmates and improve their English, while participating fully in the college experience, gaining confidence and important skills for college success.

\section{References}

Agernäs, E. (2015). Vocabulary size and type goals in advanced EFL and ESL classrooms. A review of research on lexical threshold, lexical coverage, reading and listening comprehension. Retrieved from https://gupea.ub.gu.se/bitstream/2077/38439/1/gupea_2077_38439_1.pdf

Adams, N. E. (2015). Bloom's Taxonomy of Cognitive Learning Objectives. Journal of the Medical Library Association: JMLA, 103(3), 152. https://doi.org/10.3163/1536-5050.103.3.010

Anstrom, K., DiCerbo, P., Butler, F., Katz, A., Millet, J., \& Rivera, C. (2010). A Review of the Literature on Academic

English: Implications for K-12 English Language Learners. Arlington, VA: The George Washington University Center for Equity and Excellence in Education.

Bailey, T. (2009). Challenge and Opportunity: Rethinking the Role and Function of Developmental Education in Community College. New Directions for Community Colleges, 2009(145), 11-30. 
https://doi.org/10.1002/cc.352

Bailey, T. R., Jaggars, S. S., \& Jenkins, D. (2015). Redesigning America's community colleges. Harvard University Press. https://doi.org/10.4159/9780674425934

Bisson, M. J., Heuven, W. J., Conklin, K., \& Tunney, R. J. (2014). The Role of Repeated Exposure to Multimodal Input in Incidental Acquisition of Foreign Language Vocabulary. Language Learning, 64(4), 855-877. https://doi.org/10.1111/lang.12085

Bradbury-Huang, H. (2010). What is Good Action Research? Why the Resurgent Interest? Action Research, 8(1), 93-109. https://doi.org/10.1177/1476750310362435

Cammarata, L., Tedick, D. J., \& Osborn, T. A. (2016). Content-Based Instruction and Curricular Reforms. Content-based foreign language teaching: Curriculum and pedagogy for developing advanced thinking and literacy skills, 1.

Cohen, A. M., \& Brawer, F. B. (2003). The American community college. John Wiley \& Sons.

Fisher, R., \& Engemann, J. (2009). Factors affecting attrition at a Canadiancollege. Canadian Council on learning. Retrieved March, 25, 2010.

Gibson, C. (2016). Bridging English Language Learner Achievement Gaps through Effective Vocabulary Development Strategies. English Language Teaching, 9(9), 134. https://doi.org/10.5539/elt.v9n9p134

Goldrick-Rab, S. (2010). Challenges and Opportunities for Improving Community College Student Success. Review of Educational Research, 80(3), 437-469. https://doi.org/10.3102/0034654310370163

Harris, Elizabeth A. (2018, March 20). CUNY to Smooth the Path for Remedial Students. New York Times, p. A20 (L).

Jackson, D. L., Stebleton, M. J., \& Laanan, F. S. (2013). The Experience of Community College Faculty Involved in a Learning Community Program. Community College Review, 41(1), 3-19. https://doi.org/10.1177/0091552112473145

Johnson, D. W., Johnson, R. T., \& Smith, K. A. (2014). Cooperative Learning: Improving University Instruction by Basing Practice on Validated Theory. Journal on Excellence in University Teaching, 25(4), 1-26.

Kennedy, T. J. (2006). Language Learning and Its Impact on the Brain: Connecting Language Learning with the Mind through Content-based Instruction. Foreign Language Annals, 39(3), 471-486. https://doi.org/10.1111/j.1944-9720.2006.tb02900.x

Knoblock, N., \& Youngquist, J. (2016). College-Level Sheltered Instruction: Revisiting the Issue of Effectiveness. Journal of the Scholarship of Teaching and Learning, 16(5), 49-69. https://doi.org/10.14434//josotl.v16i5.20022

Krathwohl, D. R. (2002). A revision of Bloom's taxonomy: An overview. Theory into Practice, 41(4), 212-218. https://doi.org/10.1207/s15430421tip4104_2

Krashen, S. D. (2015). Remarks on Language Acquisition and Literacy: Language Acquisition and Teaching, Free Reading, "Test-Prep"and its Consequences, The Use of the First Language, Writing, and the Great Native Speaker Teacher Debate. Indonesian JELT, 10(1), 1-17.

Kwok, J. (2010). Girl in Translation. Penguin UK.

Larsen-Freeman, D., \& Anderson, M. (2013). Techniques and principles in language teaching 3rd edition-oxford handbooks for language teachers. Oxford University Press.

Miller, J., Berkey, B., \& Griffin, F. (2015). International students in American Pathway Programs: Learning English and Culture through Service-learning. Journal of International Students, 5(4), 334-352.

Miller, J., \& Cohen, R. (2013). Longman academic reading series, 3, Pearson Education, ESL.

Mills, G. E. (2016). Action research: A guide for the teacher researcher. Prentice-Hall, Inc., One Lake Street, Upper Saddle River, New Jersey 07458.

Nation, I. S. (2001). Learning vocabulary in another language. Ernst Klett Sprachen.

Nation, I. S. P., \& Webb, S. (2011). Content-based Instruction and Vocabulary Learning. In E. Hinkel (Ed.) Handbook of research in second language teaching and learning (Vol. 2, pp. 631-644). Routledge. https://doi.org/10.1017/CBO9781139524759

Schaefer, R. T (2016). Sociology: A brief introduction, Edition 12 (Custom for CUNY H). McGraw-Hill. 
Shapiro, D., Dundar, A., Wakhungu, P. K., Yuan, X., Nathan, A., \& Hwang, Y. (2016). Time to Degree: A National View of the Time Enrolled and Elapsed for Associate and Bachelor's Degree Earners. (Signature Report No. 11). National Student Clearinghouse.

Shields, K. A., \& ODwyer, L. M. (2017). Remedial Education and Completing College:Exploring Differences by Credential and Institutional Level. The Journal of Higher Education, 88(1), 85-109. https://doi.org/10.1080/00221546.2016.1243943

Snow, M. A. (2016). Content-Based Language Teaching and Academic Language Development. Handbook of Research in Second Language Teaching and Learning, 3, 159.

Stoller, F. L., \& Fitzsimmons-Doolan, S. (2016). Content-Based Instruction. In Second and Foreign Language Education (pp. 1-14). Springer International Publishing. https://doi.org/10.1007/978-3-319-02323-6_7-1

Wallace, M. J. (2006). Action research for language teachers. Ernst Klett Sprachen.

Williams, J., Brown, K., \& Hood, S. (2012). Academic encounters level 3 student's book reading and writing: Life in society (Vol. 3). Cambridge University Press.

\section{Copyrights}

Copyright for this article is retained by the author(s), with first publication rights granted to the journal.

This is an open-access article distributed under the terms and conditions of the Creative Commons Attribution license (http://creativecommons.org/licenses/by/4.0/). 